\title{
Completing the circle: Towards the achievement of IND-equity - A Culturally relevant health equity model by/for Indigenous populations.
}

\author{
Bernice Downey, BScN, PhD \\ School of Nursing, McMaster University
}

Cite as: Downey, B. (2020). Completing the circle: Towards the achievement of IND-equity - A Culturally relevant health equity model by/for Indigenous populations. Witness: The Canadian Journal of Critical Nursing Discourse, Vol 2(1), 97-110 https://doi.org/ 10.25071/2291-5796.59

\begin{abstract}
Health equity is defined in ways that espouse values of social justice and benevolence and is held up as an ideal state achievable by all. However, there remains a troubling gap in health outcomes between Indigenous peoples and other Canadians. Public health stakeholders aspire to "close the gap" and "level the gradient" to reduce inequities though the implementation of various health equity focused strategies. The Truth and Reconciliation Commission of Canada echoes this objective and calls for self-determining structural reform to address health inequity for Indigenous peoples. In this paper, I propose an IND-equity model as a reconciliation inspired response that upholds Indigenous self-determination and is informed by diverse Indigenous ways of knowing. When adopting this model, the goal is to complete the circle and foster wholistic balance. Further development and implementation of an IND-equity model requires advocacy by all health practitioners. Nurses hold potential to lead and engage in structural reform through an Indigenous health Ally role.
\end{abstract}

Key Words: health equity, IND-equity, Indigenous knowledge, nursing, Allyship

\section{Author Note}

I am of Saulteaux-Ojibwe/Cree and Celtic heritage. My mother and my ancestors are from Lake St. Martin Manitoba. I was raised in an urban setting in Ontario for most of my life. I am a mother and a grandmother. I was a Bachelor prepared nurse for many years and worked in both in-patient/out-patient and community mental health settings. I also hold a Doctorate in medical anthropology with research interests in Indigenous health/health literacy, Indigenous traditional knowledge, and health/research system reform for Indigenous populations. 
The Canadian health policy environment has experienced a shift that aims to promote health equity. This shift was inspired by the World Health Organization's Commission on the Social Determinants of Health that was established in 2005 with a goal to foster a global movement to achieve health equity. The path forward to do so according to the Canadian Public Health Association (n.d.) was guided by three principles: First, "improve the conditions of daily life." Second, "tackle the inequitable distribution of power, money and resources" (identified as the structural drivers of daily life conditions), Third, "measure the problem, evaluate action, expand the knowledge base," and raise public awareness and workforce capacity regarding the social determinants of health. However, it is argued that an Indigenous critical lens is required in the application of these principles when addressing health inequities experienced by Indigenous peoples.

Currently, health equity is defined in ways that continue to espouse values of social justice and benevolence. For example, Health Quality Ontario (n.d.) describes health equity as "an ideal state in which all people are able to reach their full health potential and receive highquality care that is fair and appropriate from each person's perspective, no matter where they live, who they are or what they have" (p. 7). Equity focused approaches are upheld as a moral and ethical path forward to address health inequities and there are many system-level examples where equity has been included as an over-arching value to be identified. According to Kickbusch (cited in Marchildon, 2013), Canada has also taken a rights-based approach to health that acknowledges the Universal Declaration of Human Rights (United Nations, 1948) and the International Covenant on Economic, Social and Cultural Rights (United Nations, 1976). These policies signal readiness to support culturally relevant, rights-based Indigenous health equity.

\footnotetext{
${ }^{1}$ The term "Aboriginal" is used in the document to maintain consistency with the reference it is drawn from. Otherwise the term "Indigenous" is used, which is in keeping with the emergent international use of the term.
}

Public health stakeholders in Canada are actively working to address and close the health gap as part of their mandate to reduce inequities between various population groups and improve the overall health of Canadians. The overarching goal is to "close the gap" and "level the gradient." National stakeholders such as the Canadian Nurses Association (CNA, 2018) are also striving to situate the concept of social justice as central to nursing; in its position statement on Promoting Cultural Competence in Nursing (CNA, 2018), the concept of addressing health inequity is linked as contributing to the provision of cultural safety with the rationale that both concepts address social injustice and unequal power relations.

In considering the application of mainstream health equity approaches for Indigenous ${ }^{1}$ peoples, it is important to understand the socio-historical and structural factors related to their experiences of health inequity. The unpacking of barriers and issues requires an Indigenous critical lens towards making connections between Canada's colonizing relationship with Indigenous peoples and their contemporary health status. This perspective is in keeping with Smith's (1999) seminal work that acknowledges how Indigenous academics and researchers, situated in spaces of resistance and hope, are addressing social issues within a wider framework of selfdetermination, decolonization and social justice. In this paper, I provide a brief overview of the mainstream health equity environment and introduce an Indigenous, culturally relevant model of "IND-equity." The model draws on Indigenous epistemology, is informed by the United Nations Declaration on the Rights of Indigenous Peoples (United Nations, 2007), and is situated within a self-determining, rightsbased perspective. It is proposed that an INDequity model will close the gap and level the

The terms First Nations, Métis, and Inuit are terms used as appropriate to reflect the perspective of one or all three tribal groups recognized in the Constitution Act, 1867 section 7.2. 
gradient by "completing the circle," thereby, addressing health inequities experienced by First Nations, Inuit and Métis peoples in a culturally safe way.

\section{Reaping the Bounty of Inequity: Understanding the Gap}

"The historical denial of the rights of Indigenous peoples is directly linked to socioeconomic disparities, including poor health outcomes." (Hon. Jane Philpott, Former Minister of Health, 2018, p. 1650)

The Canada Health Act, introduced in 1984, espoused what eventually came to represent the principles and values that are the foundation of Canadian Medicare. These five criteria are public administration, comprehensiveness, universality, portability, and accessibility, and they were judged as standing the test of time by the Romanow Commission (2002). It is reported that the Canada Health Act appears to have had positive outcomes in reducing health disparities since Medicare was introduced. James et al. (cited in Marchildon 2013) reported that a 25year study showed a major reduction in disparity measured by the rates of death amenable to medical care. However, while life expectancy has continued to increase among Canadian males since 1980, this is not the case for First Nations, Inuit, and Métis populations in Canada.

The Public Health Agency of Canada

(PHAC) reports that health inequalities continue to exist, are persistent and for some, continue to grow. The distinction is made that many inequalities are linked with the social, political and economic disadvantages for some individuals and groups and negatively affect the achievement and maintenance of good health over their lifetime. When inequality in health outcomes or in access to supportive health resources are systematic or consistently different between population groups and can be avoided or ameliorated with collective action, they are classified as unjust and inequitable (2018). The presence of significant health inequality for Indigenous peoples is affirmed by PHAC. For example, wide gaps in life expectancy were observed between Indigenous and nonIndigenous Canadians (2018).
For those living in areas with low concentration of self-identified Indigenous people, life expectancy at birth was 12 years lower than in areas with a high concentration of Inuit with males 66.4 years and females 73.1 years. For First Nations peoples, 11.2 years lower in high concentration of First Nations people (males 67.6 years, females 73.7 years) and for Métis, 6.9 years lower in areas with a high concentration (males 71.7 years, females 78.2 years). (2018). Inequality relative to infant mortality is evident in areas where more Indigenous peoples live. For example, Inuit (3.9 times higher); First Nations (2.3 times higher) and Métis (1.9 times higher) (2018). The improvement of infant mortality over recent decades in Canada is reported as not equally distributed and is strongly linked to socioeconomic status. Infant mortality inequality is evident in areas where more Indigenous peoples live. For example, Inuit (3.9 times higher); First Nations (2.3 times higher) and Métis (1.9 times higher) (PHAC, 2018).

Suicide is clearly linked to a socioeconomic gradient with rates that increase with decreased income and education levels and increased social and material depravation. In areas where there are many people who identify as Inuit, First Nations and Métis people, suicide rates are reported respectively as, 6.5, 3.7, and 2.7 times higher than in areas with a lower concentration of Indigenous people. This shows respectively, 61.0, 29.2, and 18.6 more suiciderelated deaths per 100,000 people (PHAC, 2019). An important consideration related to the context of inequities experienced by Indigenous peoples is understanding that they are directly related to the colonial policies and practices of Western settler governments including forced relocation, the residential school system and banning of Indigenous languages and cultural practices. The presence of intergenerational trauma that is unaddressed is noted as adding to the challenges experienced by Indigenous peoples (2018).

A major structural barrier impacting the ability to accurately measure the gap between the health of Indigenous peoples and their Canadian counterparts is the lack of 
disaggregated data. This is due in part to how out of date comparative health outcomes information is, with much of it coming from the 1990s (Truth and Reconciliation Commission of Canada, 2015). Data representative of First Nations, Inuit and Métis populations is often not available, not complete or culturally inappropriate and negatively affected by fundamental power and control issues such as government-related jurisdictional issues. (Dyck et al., 2018).

Another systemic factor is that mainstream health systems and health education curriculum is informed by Western Eurocentric knowledge that lacks an inclusive space for Indigenous knowledge systems related to health and well-being for Indigenous peoples. Health infrastructure funding that emerged to establish Indigenous health organizations with mandates to address barriers such as this and to build capacity among Indigenous populations in health was terminated in 2012. The National Aboriginal Health Organization and the Aboriginal Healing Foundation were examples of Indigenous-led organizations that were making an important contribution to the Indigenous health policy and research environment. They were also supporting community-level capacity building. Without them, Indigenous-led efforts to inform the health equity policy and research environment regarding Indigenous health and well-being has been significantly diminished.

\section{Colonization, Racism, and Health} "I want to get rid of the Indian problem. Our objective is to continue until there is not a single Indian in Canada that has not been absorbed into the body politic and there is no Indian question." (Duncan Campbell Scott, as cited by Joseph Gunnell, 1998)

The legacy of the federal government's first Superintendent of Indian affairs, Duncan Campbell Scott, continues to negatively impact Indigenous peoples' health and well-being in contemporary times. Many continue to experience harsh judgement, discrimination, and a rejection of who they are and how they live.
The link between the Canadian government's assimilation policy and legislation including the Indian Act and residential schools must be considered in the assessment of serious health inequity among First Nations, Inuit, and Métis peoples. For example, proponents of trauma theory, Duran and Sotero (cited in Aguiar \& Halseth, 2015) argue for an acknowledgement of the cumulative effect of earlier forms of injustice and oppression that is internalized and leads to inter-generational shame and hopelessness. For many, historical trauma has created inequity related to social determinants such as lower levels of income and education, among others, and when combined with experiences of cultural identity erosion and decreased pride in self, continues to perpetuate trauma.

Allan and Smylie (2015) explore the role of racism in the health and well-being of Indigenous peoples in Canada. Racism has played a foundational role in the development and maintenance of the Canadian nation state. The colonization process was fueled by racist beliefs and ideas about Indigenous peoples, values, ways of knowing and being, customs and practices. These authors note the importance of acknowledging that these race-based beliefs "served to justify acts of racial discrimination, including violence, cultural genocide, legislated segregation, appropriation of lands, and social and economic oppression enacted through such policies as the Gradual Civilization Act and the Indian Act" (Allan \& Smylie, p. 1). A critically important point here, is the link between policies and practices that emerged from colonial ideologies and the profound negative impact on the lives and well-being of Indigenous peoples that impacted access to education, housing, food security, employment, and healthcare. This phenomenon can be situated within a frame of structural violence, a concept that can be linked to the occurrence of inequity experienced by some groups when there is a much lower life expectancy than others with no identifiable agent responsible for such an avoidable discrepancy (Vorobej, 2008). The next section provides discussion on key socio-cultural factors of Indigenous knowledge systems and self- 
determination and how they are linked to the concept of equity for Indigenous populations.

\section{IND-equity: Embracing our Indigeneity, our Knowledge Systems and our Power}

The notion of equity is situated as an important value to be embedded within a foundation of healthcare approaches for all. In general, mainstream health systems draw on concepts that are embedded in a European, colonial, or dominant mainstream worldview. For example, person-centered care, patientsafety, population-health, social determinants of health and distribution of power (Public Health Association of Canada, 2016). Equity is defined as the quality of being fair and impartial and is associated with notions of "fairness, justness, impartiality, and egalitarianism;" it is a concept associated with addressing individual needs (Dictionary.com, n.d.).

As various stakeholders strive to address inequity related health reform, it is important to be cautious when considering an umbrella approach towards achieving "equity for all," particularly, when applying this approach to ameliorate the health inequities experienced by Indigenous peoples. This approach risks further marginalization of Indigenous peoples in that it would be contrary to their recognition as unique peoples in the Canadian Charter of Rights.

Further, there is a misalignment with the United Nations Declaration on the Rights of Indigenous Peoples $^{2}$ (UNDRIP) positioning of Indigenous peoples' self-determining right to health. For example, (UNDRIP, 2008) Article 24.2 upholds Indigenous peoples' "equal right to the enjoyment of the highest attainable standard of physical and mental health." Further, in UNDRIP Article 23, Indigenous peoples' right to determine and develop priorities and strategies for exercising their right to

2 The UNDRIP is a United Nations-led 25-year collaboration with Indigenous Peoples around the world and adopted by the UN Permanent Forum on Indigenous Peoples in 2007. The Declaration calls on development in areas of health and social policy and programmes is affirmed.

The Truth and Reconciliation Commission of Canada's final report (Truth and Reconciliation Commission of Canada, 2015), Call to Action \#19, calls for the federal government to establish measurable goals to identify and "close the gap" in health outcomes between Aboriginal and non-Aboriginal communities, and to publish annual progress reports and assess long-term trends. In keeping with a reconciliation approach, health system structural reform calls for Indigenous selfdetermining approaches that maintain the Commission's implementation principles and that are in keeping with the notion of "nothingfor-us-without-us" (Canadian Indigenous Nurses Association, 2016).

The National Collaborating Centre for Determinants of Health (NCSDH, 2013), one of the Public Health Agency of Canada's six collaborating centres, advocates for the use of a continuum of health equity approaches described as universal, targeted, blended, targeteduniversal and proportionate universal. The NCSDH stipulates that decision makers must assess the perceptions, biases, and evidence they bring to the policy or program development process. Further, while both universal and targeted approaches have strengths and challenges, a blended approach is noted as frequently guiding interventions in order to "level the gradient." However, from an Indigenous critical, rights-based perspective, it is argued that the blended approach should be expanded to achieve a more culturally relevant perspective. It is proposed that this objective can be achieved through the development of an INDequity model; one that addresses the need to decolonize mainstream approaches of health equity for Indigenous peoples.

Member States to adopt and adhere to UNDRIP as minimum standards for the survival, dignity, and well-being of the Indigenous peoples of the world. 
The IND-equity model draws on Indigenous epistemologies (the way we know things) and ontology (about what things are). It upholds our Indigeneity, our Indigenous knowledges, languages and cultures. It is about our right to self-determination that frames the collective expression of our needs with respect to health and well-being (Downey, 2019). The role of the health care practitioner is an important element towards the implementation of an IND-equity model. Indigenous health care practitioners are able to inform their efforts. The next section examines the perspective of Indigenous nurses and also provides a personal story regarding the process of 'picking up our bundles'; an analogy that can be applied to selfreflection and the integration of one's own Indigenous ways of knowing to their work.

\section{Indigenous Nursing Perspectives}

In the development of a health equity model for Indigenous peoples, it is important to understand how healthcare practitioners' practice can contribute to a successful implementation process that is in keeping with a reconciliation approach. For Indigenous nurses (and other Indigenous health practitioners) the truth of how Indigenous peoples historically have been asked to sacrifice their own Indigenous values and affirm alien, settler values must be affirmed. They were encouraged to avoid unnecessary exclusion by fitting in with the Eurocentric version of society. YoungbloodHenderson (2000, p. 249) discusses the concept of decolonization within a legal context, describing the process of acquiring freedom through breaking the silence and "retaking" possession of one's humanity and identity. His reflections on how to decolonize one's thoughts and beliefs holds relevance to the health context and more specifically, how the notion of equity, as a colonial value, has been upheld as a tool of inclusion for Indigenous peoples. He notes that to speak, initially one must share Eurocentric thought and discourses. Thus, Indigenous academics (and health practitioners) are required to engage in the language of the dominant culture's healthcare policy analysts and researchers. However, Youngblood-Henderson advocates that to exist with dignity and integrity, the acquired European thoughts and discourses must be renounced and one has to live with the ambiguity of thinking against oneself. What follows is that we must reclaim our own ways of knowing to create Indigenous health equity models to assist us in navigating in an unexplored territory. Youngblood-Henderson calls for a process of developing a new postcolonial synthesis of knowledge based on reinventing the Indigenous discourse on heritage and language. This imperative can be applied to all health practitioners.

Nursing policy leaders such as the Canadian Nurses Association (2018) call for all nurses to engage in self-reflection on their own cultural values and how they impact the way they provide care as an indicator of cultural competence. All health practitioners, nonIndigenous and Indigenous, educated in health science programs with curriculum that embeds Western European knowledge must also engage in the renouncement process for which Youngblood-Henderson advocates in order to facilitate the acknowledgement and uptake of Indigenous ways of knowing in health equity approaches for Indigenous peoples.

For Indigenous health practitioners, this also requires an acknowledgement of our own Indigeneity and an understanding of how we harmonize our own ways of knowing and healing into the work we do. This experience can be described as "picking up our bundle"; an expression that captures a self-reflective process of the acknowledgement of our Indigeneity and our ancestral knowledge and wisdom and applying this knowledge to the work we do as healers.

\section{Self-Reflexive insights: from nursing to medical anthropology and the contribution of an IND-equity model.}

My own process of picking up my bundle has been a career-long endeavor that began with reflection about why I chose a nursing career. I was guided by my mother who upheld an image of a nurse that no doubt was 
influenced by the lived experience of accessing government run health services in a small First Nations community. Her experience was that healthcare services were provided by nonIndigenous nurses and physicians. Her rationale for recommending nursing as a career choice was expressed to me as: "You will always be respected; you will always have a job and you can travel." While she was right on all three counts, what she couldn't advise me about were the challenges I would experience related to the cognitive dissonance and emotional stress of being an Indigenous woman and a health professional engaged and bound by professional practice guidelines embedded within a dominant Western worldview. A bio-medical worldview that proved to have jagged edges when trying to align them with an Indigenous perspective of health and well-being.

It is both interesting and troubling for me to know that a deeper cultural consciousness raising regarding the health and social inequities experienced by Indigenous peoples was ignited by my professional role as a nurse with clinical, administrative, and policy/research experiences. My nursing education ill-prepared me to understand the complexity and inequalities pervasive among Indigenous populations in Canada. I only came to understand the link between Indigenous health inequity and the influence of multi-jurisdictional government control after several years working in mainstream health organizations. My sociopolitical consciousness raising was fueled by a recognition of the ongoing colonizing impact of settler government policies and civil society uptake and engagement with Indigenous peoples that seemed to perpetuate the status quo. Over time, working in Indigenous organizations tethered to government funding with limited capacity and ability to influence positive and self-determining reform, led me to seek the attainment of graduate level education. A medical anthropology $\mathrm{PhD}$ program allowed for the pedagogical flexibility required to delve deep into an academic exploration of the

\footnotetext{
${ }^{3}$ William Commanda, an Algonquin elder and former
} chief of the Kitigan-zibi Anishinabeg First Nation, connection between Indigenous knowledge, traditional healing, and an improved overall health status for Indigenous peoples. This educational path included the immersion into a deep self-reflection regarding my identity and the embodiment of Indigenous cultural knowledge related to the socio-cultural history and experience of my family and ancestors. The achievement of a Doctorate degree empowered me to amplify Indigenous voices regarding social and health related inequality among postsecondary educators and health system stakeholders. This, coupled with a post- truth and reconciliation environment of calling those in positions of influence to action, shone a spotlight and created a forum to address the need for structural change in both education and health systems. My dissertation posited that the harmonization of health systems and education curriculum inclusive of both Western and Indigenous worldviews would facilitate the achievement of this goal.

\section{Reclaiming Indigenous Nursing Knowledge}

"To cherish knowledge is to know Wisdom. Wisdom is given by the Creator to be used for the good of the people. In the Anishinaabe language, this word expresses not only "wisdom," but also means "prudence," or "intelligence." We need this old knowledge in our teachings to get through this new age" (Elder William Commanda, ${ }^{3}$ June 10, 2010. Message to the Algonquins of the Ottawa River Watershed)

Battiste and Youngblood Henderson (2000) describe Indigenous knowledge as the manifestation of human knowledge, heritage, and consciousness and is a means of ecological order. Indigenous Knowledge covers a range of values and beliefs present in First Nations, Inuit, and Métis peoples' ways of knowing and being. It includes knowledge stemming from various creation stories, traditional healing methods, language, traditional parenting, ceremonies, and spirituality. While it is acknowledged that

was the wampum belt keeper for the Seven Fires Prophecy. 
literature on the topic of Indigenous knowledge does exist, it is a newly emerging body of literature and therefore, is limited in scope and depth (Battiste, 2002). However, several contemporary Indigenous scholars (Dion Stout 2003; Smith 1999; Cajete 2000) have articulated the complex nature and importance of Indigenous knowledge towards the development of culturally safe services for Indigenous populations. An Indigenous pedagogy inherently respects and acknowledges the plurality of knowledge systems, and Indigenous nurse scholars, as noted in the next section, are contributing to this discourse.

Historian, Mary Jane Logan McCallum (2014) provides a historical account of women's labour and through the tracing of the role of Indigenous nurses and their journey of finding their collective voice within an emerging health professional discourse regarding Indigenous identity, language, and education. Their work began to influence nursing approaches to health promotion, prevention, treatment, and education. As nurses critically reflect on their own diverse systems of Indigenous knowledge and healing, often there is a reclamation of their own Indigenous nursing knowledge. The notion of Indigenous nursing knowledge is rooted in the notion of a "unique expertise" that Jean Goodwill, an Indigenous nurse and founder of the Registered Nurses of Canadian Indian Ancestry articulated as the essence of Indigenous nursing (Canadian Indigenous Nurses Association, 2016, p. 14). This notion of Indigenous nurses' unique expertise has evolved with various Indigenous nurse-thought leaders contributing to the discourse. Indigenous nurses in Canada have been combining their Western education with a firm grounding in their own languages, cultures, and healing traditions to shape the field of Indigenous-nursing knowledge and it is utilized to advance and shape the current context of nursing practice. Earl Nowgesic, an Anishinaabe nurse and academic acknowledges the collective work related to describing an Indigenous nursing specialty ("Aboriginal Health Nursing")' a significant marker in this process is defined as "the way in which nursing care is provided to Aboriginal clients; and also the way in which nursing interventions are targeted towards Aboriginal communities and populations" (Aboriginal Nurses Association of Canada, 2001:3). Contemporary Indigenous nursing knowledge can be described as the knowledge that all Indigenous nurses hold intrinsically; a way of knowing linked to their Indigeneity and both their lived cultural and professional nursing experience. This knowledge is cultivated and harmonized in their work related to policy, education, research, and practice. The following section delves deeper into how

Saulteaux/Ojibwe language and knowledge can inform an IND-equity model.

\section{Paydshiquin - Completing the Circle and Informing an IND-equity Model}

As noted previously, an IND-equity

model signals the need to decolonize mainstream approaches of health equity for Indigenous peoples--a model that is informed by Indigenous ways of knowing. Various Indigenous thought leaders and Elders are drawing on Indigenous epistemologies and engaging in a reflective and critical discourse regarding the notion of equity as it relates to Indigenous peoples. For example, Dion Stout, a Cree nurse, researcher and academic expresses her understanding regarding the notion of equity that captures the essence of the concept of the post-colonial re-synthesizing of knowledge based on reinventing or reclaiming the Indigenous discourse. She calls for a paradigm shift that will "fully exploit the human agency and traditions of Indigenous people," draws on Cree concepts of "nahi" or fairness rather than "tipi" or equal, and calls for a focus on explicit values and inequities in order for nahi to be realized (Dion Stout, 2012, p. 11).

Mohawk Elder Jan Kaheti:io Longboat during a discussion with this writer on Indigenous perspectives of equity drew on the example of "starling murmuration"; a phenomenon of starling movement in flight where they twist and turn and change direction at a moment's notice simultaneously and 
without crossing another's path (J. Longboat, personal communication, February, 2016). Elder Longboat described this natural phenomenon as "spiritual energy," noting that we are all surrounded by this energy. Similar to this starling behavior pattern, we as humans are interconnected and move together spiritually. We are collectively moving together and are part of a whole, but each of us has our gifts that we contribute and therefore, there is an equality in this process.

Ojibwe scholars Peacock and Wisuri (2002) discuss the notion of balance as another example of an Indigenous worldview that can inform an Indigenous concept of health equity. The notion of balance can be closely linked to the achievement and maintenance of wellness. One must attend to and maintain a balance between the physical, emotional, and spiritual parts of self in order to be whole. The definition of balance is associated with an "even distribution," "stability," and "equilibrium;"- a condition in which different elements are "equal". However, the emphasis leans to an inter-connectedness that reflects how those elements are intertwined and represent a whole that is the sum of its parts. Yet, the notion of equity from a Western worldview implies that two entities are equal (Downey, 2014).

These diverse Indigenous perspectives provide a glimpse into how Indigenous ways of knowing and doing can inform an IND-equity model. From a Saulteaux/Ojibwe perspective, the notion of paydshiquin, a Saulteaux word meaning to create a constant such as a circle, can be applied to the concept of "completing the circle" (D. Stagg, personal communication, April 2020). Paydshiquin is considered as a way to frame Indigenous centric ways of living well that foster a state of wholistic balance in the physical, emotional, mental and spiritual realms.

Paydshiquin can also be linked to how we see the world around us; the sun, the moon, mother earth, or the circular symbol of the medicine wheel. Instinctually, we aspire to "close" the circle in a way that suggests a constant, a completeness, and a balance. The achievement of a collective voice for example, closes the circle in a community or group context. We refer to a cyclical journey in life versus linear measurements of progression. We move around the "wheel" to achieve wholistic balance in all realms of being. The concept of wholism is central to the notion of completeness. Absolon (2010) draws on Indigenous wholistic theory described as "whole, ecological, cyclical and relational" to emphasize that circles have been used by our ancestors as an effective tool to develop multi-level circular healing strategies for thousands of years. Further, that wholism in the Indigenous context considers the connections and the concept that "we are all related" begins to make sense as we perceive each aspect in relation to the whole. Absolon's perspective on the use of circles supports the application of paydshiquin to the concept of completing the circle.

Paydshiquin can also be described as a way of "coming back around"; a process of reclamation as we self-determine how to achieve fairness or equity. The reclamation is about "picking up our bundles" and in the spirit of self-determination, drawing on our own culture, language, values and beliefs and infusing them into how we address health inequity. It is argued that this IND-equity model will increase our agentic capacity, foster a wholistic state of wellbeing, and ultimately lead to improved health status.

The ongoing work to further develop an IND-equity model requires both advocacy and action from non-Indigenous health practitioners, policy makers, and educators towards creating a space for Indigenous knowledge in the health equity paradigm. Indigenous knowledge sources are critically important for understanding Indigenous beliefs and values regarding health and well-being and in turn, for developing culturally relevant and empowering health equity approaches for Indigenous peoples. This work to articulate a self-determining model to address health inequity is in keeping with Indigenous peoples' right "to maintain, control, protect and develop their cultural heritage, traditional knowledge and traditional cultural expressions" as per Article 31.1 in the United Nations Declaration on the Rights of Indigenous 
Peoples (United Nations, 2007). The task of advocacy can be achieved through the process of Indigenous "Allyship" "which is described in the next section.

\section{Health Practitioners: The need for Indigenous Health Allies}

The Truth and Reconciliation Commission of Canada (2015) reports that reconciliation is about establishing and maintaining a mutually respectful relationship between Aboriginal and non-Aboriginal peoples in Canada (p. 6) and further, specifically calls on nursing educators to be responsive with education related Calls to Action (p. 164). Health leaders and the organizations they work for will play a critical role in developing the partnerships needed to implement solutions (Richardson \& Murphy, 2018). Within this process of reconciliation, Allyship means that the individual recognizes settler privilege and takes action to challenge and work towards addressing the barriers that Indigenous peoples and communities face (Laurentian University, n.d.). After five years from the release of the Truth and Reconciliation Commission's Final Report (2015), are healthcare practitioners and educators prepared and confident in their ability to collaborate with Indigenous peoples to address health inequity for Indigenous populations? Those in positions of power and decision-making likely are still ill-prepared to influence the policy changes required to move the health inequity agenda forward with Indigenous populations. This can be attributed to both the lack of Indigenous health curriculum in post-secondary health science programs and the level of self-education they may or may not have engaged in to facilitate understanding of sociohistorical factors related to the context of Indigenous health inequity in Canada. For most, this will then play out in how systemic change takes place-or not.

\footnotetext{
4 An emerging concept in the realm of advocacy for Indigenous people's issues in that of an Indigenous "Accomplice." The Allyship concept's purpose is to achieve equity and inclusion through the use of one's
}

An important system level consideration in the work to address health inequity for Indigenous peoples is the role of the health practitioner. From an inter-professional perspective, all health practitioners providing health services for Indigenous people need to be prepared to support and facilitate an IND-equity model. There is a critical opportunity and responsibility for education regarding the health Ally role to amplify the voices of Indigenous people and contribute to closing the gap in measurable health outcomes.

In the spirit of "nothing for us - without us" (Canadian Indigenous Nurses Association, 2016) as an expression of Indigenous selfdetermining leadership, health practitioners, policymakers, educators, and researchers must endeavor to co-create targeted equity-based solutions such as an IND-equity model alongside Indigenous peoples. An important element of this work is both supporting and taking action to realize change at both the individual and institutional level. Nursing Allyship efforts should be guided by the knowledge and expertise of Indigenous nurse experts and by Indigenous inter-professional health practitioners who have been advocating and advancing change in the interest of Indigenous peoples' health and well-being. The focus should be on strategically implementing diverse IND-equity models that ultimately will lead to the amelioration of systemic barriers linked to health inequity and the achievement of improved health status.

Emerging resources (see Laurentian University, 2019) related to Indigenous Allyship describe this role as meaning that an individual recognizes the privilege that settler cultures hold and take for granted. There is also an expectation that challenging and working towards addressing barriers is part of the role. The first step in the development of an Ally role is self-reflection and education. Cultural safety training is a tool to address service provider bias

power and privilege, while an Accomplice is expected to engage in the anti-colonial struggle by attacking colonial structures and ideas. 
related to the ongoing legacy of colonization. Emerging evidence indicates that unconscious bias and stereotyping do lead to delayed treatment and misdiagnosis, leading to poorer health outcomes. The recent awareness and acceleration of Indigenous Cultural Safety training among non-Indigenous health practitioners and educators is an indicator of the self-education that is currently underway as more and more health institutions are gaining traction in their efforts to respond to the Truth and Reconciliation Commission of Canada (2015) Calls to Action (Ontario Indigenous Cultural Safety Program, 2017).

Nursing policy and decision makers often rely on collaboration with Indigenous leaders/educators and communities to inform their work. To avoid placing additional burden on Indigenous nursing leaders/educators and community partners, meaningful consultation regarding health and well-being services and programs, education and research needs to be thoughtfully negotiated, and the use of tools such as an agreement template may be used. A post truth and reconciliation process should uphold the Truth and Reconciliation Commission's Calls to Action and the selfdetermining implementation principles that have been laid out in the final report (Truth and Reconciliation Commission of Canada, 2015). Indigenous health leaders are being recruited both formally and informally to support institutional efforts to respond to the Truth and Reconciliation Commission's (2015) Calls to Action.

\section{Conclusion}

Allyship efforts emerging in a post-truth and reconciliation environment need to be guided by disciplinary and institutional levels of commitment to the achievement of IND-equity. The amelioration of Indigenous health inequities through the facilitation of paydshiquin will be fostered by both the harmonization of biomedical and Indigenous worldviews and engagement in structural reform. The cocreation of spaces for inclusion of Indigenous knowledges and traditional healing in both education and clinical environments requires rigorous advocacy efforts to educate and engage non-Indigenous educators, administrators and clinicians and inform their process to both understand and support this work. The point can also be made that some Indigenous peoples in these roles would benefit from further education as well. Their lived experiences may be the severance or detachment from their culture for various reasons related to the negative impact of colonization such as attending residential school or being in foster care.

The health equity reform process requires the development of culturally relevant curriculum, policy and culturally safe practice that is informed by both TRC and UNDRIP directives. Strategic effort also needs to be fiscally supported and engage an appropriate level of human resources to be effective in implementing real and effective change. Remuneration protocols for Elders and other wisdom keepers need to adequately cover their expenses and support recognition of their expertise. The concept of paydshiquin is considered as a way to promote Indigenous centered ways of living well within the physical, emotional, mental, and spiritual realms. An IND-equity model is a culturally relevant health equity model that signals the need to decolonize mainstream notions of equity for Indigenous peoples. The development, application and evaluation of IND-equity reflects the needs of diverse Indigenous populations and identifies implementation strategies as the work that lies ahead.

As the dialogue among and between Indigenous health Allies regarding the need to address Indigenous health inequity continues to emerge, nurses are well situated in key education, research, policy, practice and leadership roles and hold true potential to both foster and contribute to the adoption of an INDequity model, thereby increasing the opportunity to improve health outcomes with First Nations, Inuit, and Métis peoples. The Truth and Reconciliation Commission of Canada's (2015) Calls to Action should inspire the realization of this potential to mitigate the risk of perpetuating Indigenous health inequity. 


\section{References}

Aboriginal Nurses Association of Canada. (2001). An Aboriginal nursing specialty. Ottawa.

Absolon, K. (2010). Indigenous wholistic theory: A knowledge set for practice. First Peoples Child and Family Review, 5(2), 74-87.

https://fpcfr.com/index.php/FPCFR/artic le/view/95

Aguiar, W., \& Halseth, R. (2015). Aboriginal peoples and historic trauma: The processes of intergenerational transmission. National Collaborating Centre for Aboriginal Health. https://www.ccnsanccah.ca/Publications/Lists/Publications /Attachments/142/2015-04-28-

AguiarHalseth-RPTIntergenTraumaHistory-EN-Web.pdf

Allan, B., \& Smylie, J. (2015). First peoples, second class treatment: The role of racism in the health and well-being of Indigenous peoples in Canada. The Wellesley Institute. https://www.wellesleyinstitute.com/wpcontent/uploads/2015/02/Full-ReportFPSCT-Updated.pdf

Battiste, M., \& Youngblood Henderson, J. S. (2000). Protecting Indigenous knowledge and heritage: A global challenge. Purich Publishing Ltd.

Battiste, M. (2002). Indigenous knowledge and pedagogy in First Nations education: A literature review with recommendations. Prepared for the National Working Group on Education and the Minister of Indian Affairs Indian and Northern Affairs Canada (INAC), October 31, 2002.

https://www.afn.ca/uploads/files/educati on/24._2002_oct_marie_battiste_indige nousknowledgeandpedagogy_lit_review _for_min_working_group.pdf
Cajete, G. (2000). Native science: Natural laws of interdependence. Clear Light Publishers.Canadian Public Health Association. (n.d.). Canada's leadership in addressing the social determinants of health. Canadian Public Health Association. https://www.cpha.ca/canadasleadership-addressing-socialdeterminants-health

Canadian Indigenous Nurses Association. (2016). Nothing for us - without us. Canadian Indigenous Nurses Association collaborative Indigenous partnership framework: Supporting our unique expertise: Indigenous nursing knowledge. The Indigenous Nurse, Spring, p. 14.

Canadian Nurses Association. (2018). Position statement: Promoting cultural competence in nursing. https://www.cna-aiic.ca//media/cna/page-content/pdfen/position statement promoting cultur al_competence_in_nursing.pdf?la=en\&h ash=4B394DAE5C2138E7F6134D59E5 05DCB059754BA9

Dictionary dot com. (n.d.). Definition of equity. Dictionary dot com. http://www.dictionary.com/browse/equi y

Dion Stout, M. D. (2012). Ascribed health and wellness, Atikowisi miýw-āyāwin, to achieved health and wellness, Kaskitamasowin miýw-āyāwin: Shifting the paradigm. The Canadian Journal of Nursing Research $=$ Revue canadienne de recherche en sciences infirmieres, 44(2), 11-4.

Dion Stout, M., \& Kipling, G. (2003). Aboriginal people, resilience and the residential school legacy. Aboriginal Healing Foundation. http://www.ahf.ca/publications/researchseries

Downey, B. (2014). Diaspora health literacy: Reclaiming and restoring Nibwaakaawin (wisdom) and mending 
broken hearts.

https://macsphere.mcmaster.ca/bitstream

/11375/16449/1/Downey\%20Dissertatio

n_Final_Oct\%2015.pdf

Downey, B. (2019, December). IND-equity:

Indigenous peoples right to health -

who's listening? Manuscript in

preparation.

Dyck, LA., Snelling, S., Morrison, V., HaworthBrockman,M., Atkinson, D. (2018). Equity reporting: A framework for putting knowledge mobilization and health equity at the core of population health status reporting. Health Promotion and Chronic Disease Prevention in Canada. Research, Policy and Practice, 38(3). https://doi.org/10.24095/hpcdp.38.3.02

Gunnell, J. (1998). Speech to the British Columbia legislature, December 2, 1998. BC Studies, 120 (Winter 1998/99), $5-10$. https://ojs.library.ubc.ca/index.php/bcstu dies/article/view/1474/1518

Health Quality Ontario. (n.d). Health Quality Ontario's Health Equity Plan. Health Quality Ontario. https://www.hqontario.ca/Portals/0/docu ments/healthquality/Health_Equity_Plan_Report_En. pdf

Laurentian University. (n.d.) How to be an Ally to Indigenous peoples. https://laurentian.ca/indigenousprograms/how-to-be-an-ally

Marchildon, G. (2013). Health systems in transition ( $2^{\text {nd }}$ ed.): Canada: Health system review 2013. University of Toronto Press.

McCallum, M. (2014). Indigenous women, work and history 1940-1980. University of Manitoba Press.

National Collaborating Centre for Determinants of Health. (2013). Let's talk: Universal and targeted approaches to health equity. http://nccdh.ca/resources/entry/lets-talkuniversal-and-targeted-approaches

Ontario Indigenous Cultural Safety Program.
(2017). New brand for Ontario Indigenous Cultural Safety Program. Anishinabek News, June 16, 2017. http://anishinabeknews.ca/2017/06/16/n ew-brand-for-ontario-indigenouscultural-safety-program/

Peacock, T., \& Wiser, M. (2002). Ojibwa: We look in all directions. Afton Historical Society Press.

Philpott, Hon. J. (2018). Canada's efforts to ensure the health and wellbeing of Indigenous peoples. The Lancet, 391(10131), 16501651.https://doi.org/DOI:10.1016/S0140 -6736(18)30179-X

Public Health Agency of Canada. (2018). Infographic: Inequalities in infant mortalities in Canada. Retrieved from website: https://www.canada.ca/en/publichealth/services/publications/scienceresearch-data/inequalities-infant$\underline{\text { mortality-infographic.html }}$

Public Health Agency of Canada. (2018). Key Health Inequalities in Canada. A National Portrait. Retrieved from website:

https://www.canada.ca/content/dam/phacaspc/documents/services/publications/scienceresearch/key-health-inequalities-canadanational-portrait-executivesummary/key health inequalities full reporteng.pdf

Richardson, L., \& Murphy, T. (2018). Bringing reconciliation to healthcare in Canada. Wise practices for health leaders. HealthCareCan. https://www.healthcarecan.ca/wpcontent/themes/camyno/assets/document/Report s/2018/HCC/EN/TRCC_EN.pdf

Romanow Commission. (2002). Commission on the future of health care in Canada. The Romanow Commission. Government of Canada. https://www.canada.ca/en/healthcanada/services/health-caresystem/commissions-inquiries/federalcommissions-health-care/commission- 
future-health-care-canada-romanowcommission.html

Smith, L. T. (1999) Research and Indigenous peoples: Decolonizing methodologies. Zed Books

Truth and Reconciliation Commission of Canada. (2015). Honouring the truth, reconciling for the future: Summary of the final report of the Truth and Reconciliation Commission of Canada. http://www.trc.ca/

United Nations. (1948). The universal declaration of human rights. https://www.un.org/en/universaldeclaration-human-rights/index.html

United Nations. (2007). United Nations declaration on the rights of Indigenous peoples. https://www.un.org/development/desa/in digenouspeoples/declaration-on-therights-of-indigenous-peoples.html

Vorobej, M. (2008). Structural violence. Peace research, 40(2), 84-98. www.jstor.org/stable/23607799

Wonderopolis. (n.d.). Wonder of the day \#825: What is murmuration? https://www.wonderopolis.org/wonder/ what-is-a-murmuration

Youngblood-Henderson, S. (2000). Ayukpachi: Empowering aboriginal thought. In M. Battiste (Ed.), Reclaiming Indigenous voice and vision (pp. 248 - 271). UBC Press. 